\title{
Analysis of liquefaction risk of sterile material in the inner dump of North Pesteana quarry in the conditions of flooding of the remaining gap
}

\author{
Izabela Maria Apostu*, Maria Lazar, and Florin Faur \\ University of Petrosani, Faculty of Mining, Department of Environmental Engineering and Geology, \\ University Street, no. 20, Romania
}

\begin{abstract}
In the conditions of the dump slopes formed by loose rocks, predominantly sandy rocks, which are at the first saturation, there is a significant risk of sliding due to liquefaction of the waste material. The liquefaction process may be triggered by hydrological, mechanical or seismic factors. In saturated sand, the space between the solid granules is completely filled with water, and the pore water pressure, which increases as the depth increases, causes the grains to move away from each other, so the material is flowing. Among the methods for assessing the liquefaction potential of rock masses/deposits can be summarized: historical phenomena observations, studying the liquefying potential area maps, analysis of geological process that led to the creation of rock deposits and the nature of rocks. The paper aims at assessing the risk of liquefaction of sterile material in the inner dump of the North Pesteana quarry during the flooding of the remaining gap, since the preliminary studies found that the sterile material consists of important fractions of sand, indicating that there is liquefaction potential. The risk of liquefaction was determined taking into account the liquefaction potential, the nature of the objectives in the area and the probability of liquefaction.
\end{abstract}

\section{Introduction}

According to the literature [1] the risk of liquefaction is one of the major geotechnical hazards that may occur at the final slopes of the remaining gaps under the conditions of their flooding.

The phenomenon of liquefaction can be triggered by the action of hydrological, mechanical or seismic factors.

Under the action of groundwater and generally, in the conditions of saturation of loose and sandy rocks and the manifestation of pore water pressure, the rock particles are surrounded by a water film, the material behaving like a liquid.

Vibrations caused by earthquakes, explosions, heavy vehicles, ground and underground traffic, and seismic shocks during earthquakes can also influence this phenomenon. [2]

\footnotetext{
* Corresponding author: izabelamaria.nyari@yahoo.com
} 
Examples of liquefaction phenomena can be given at European level. Germany is one of the countries that has encountered numerous liquefaction problems (exmples Laubusch (1962), Lippen Nord (1984), Skado (1984), Sedlitz (1987) și Lohsa II (1995) mining exploitation), but it is also one of the best examples of good practices of rehabilitation of areas affected by liquefaction. In 1998 a liquefaction phenomenon occured on the embankment of Koschen dam. It resulted in the destruction of some installations, large losses of land and people exposure to dangerous conditions. The main cause was the liquefaction of loose and saturated sands that caused a significant increase in the groundwater level relative to the water level in the lake. There have been several works to restore the balance of the slopes. [3]

The literature [1], in order to assess the liquefaction potential, presents several methods based on historical criteria (observations of the phenomena manifested in earlier periods and the study of the areas with the potential for liquefaction), geological criteria (the type of geological process that led to the creation of deposits of rocks with liquefying potential) or lithological criteria.

So far, in North Pesteana mining perimeter there were no liquefaction phenomena, but given the sand fraction present in the dump $(\approx 48 \%)$ and the rise of the water level in the remaining gap during the flood, the problem of liquefaction can become a real one.

\section{Properties of liquefiable rocks}

The sensitivity to liquefaction of coarse-grained rocks depends mainly on the degree of compaction, the degree of loosening, the size of the mineral granules, the uniformity of particle distribution, the permeability and the water-disposing capacity of the rocks, the particle shape (degree of rounding) and roughness of the particles.

Depending on the granulometric distribution, delimitation intervals of sands prone to liquefaction have been established for sandy rocks (Figure 1).

As a result of granulometric analyzes carried out in the laboratory on samples taken from the North Pesteana perimeter, it has been observed that some of the resulting granulometric curves overlap the high potential of the liquefaction interval. In addition, knowing the important fraction of sandy rocks in the dump, the issue of liquefaction of the waste material was raised in the conditions of flooding of the remaining gap.

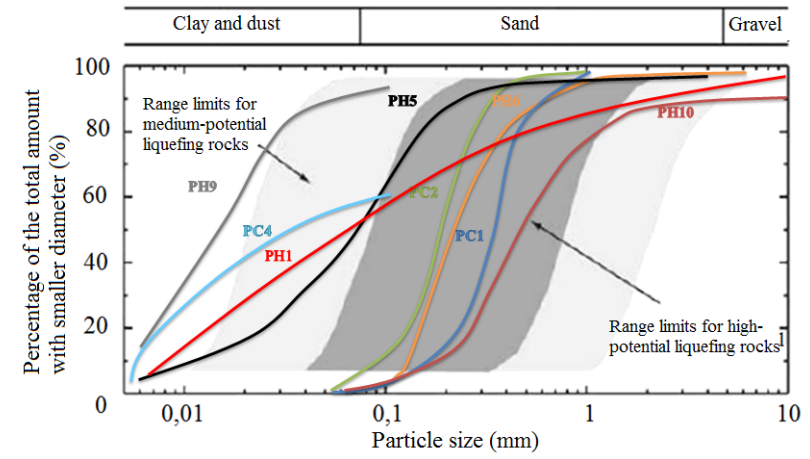

Fig. 1 The granulometric distribution of sands prone to liquefaction [4]

According to Figure 1, sands with uniform granulometry present a significantly higher liquefaction risk than in the case of a mixture of particles with uneven granulometry.

Vulnerable rocks, which may lose their resistance and may enter the liquefaction process, are part of the following categories of sand: sandy-clayey dust, clayey dust, clayey sand, dusty sand, sand and fine sand. According to the literature, vulnerable rocks to 
liquefaction have the following characteristics: clay content $<10 \%$; flow limit $<35 \%$; water content $>0.9 \times$ flow limit $(31.5 \%)$. [5, 6]

\section{Assessment of the risk of liquefaction of the waste material}

The risk associated with geotechnical phenomena is the quantitative evaluation expressed in monetary units, the material or numerical losses, the human casualties recorded as a result of the catastrophes caused by their occurrence.

The liquefaction risk $(\mathrm{R})$ is defined as the product of the liquefaction probability (Pr) and the vulnerability of the objectives in the area according to the technical state of the inner dump (V) (1):

$$
R=\operatorname{Pr} \cdot V
$$

Analyzing the list of the strongest earthquakes in Romania recorded during the last millennium, it is noticed that in Gorj county, on which the North Pestera mining perimeter is located, no notable earthquakes which would cause significant effects in the studied perimeter, were recorded. [7 - 10]

Within the North Pesteana mining perimeter, vibrations result from the operation and transportation of heavy equipment in the quarry (excavators with portholes, conveyor belts, bulldozers, other heavy vehicles etc.). The county road DJ 674 is about $200 \mathrm{~m}$ away from the western side of the mining perimeter, and road traffic is relatively low. The national road DN 66, with intense traffic, is at least $500 \mathrm{~m}$ away from the eastern side of the mining perimeter, between the DN 66 and the Pesteana Nord perimeter being the regularized course of the Jiu River.

Taking into account the synthesized seismic activity and vibration actions in the North Pesteana area, it can be said that earthquakes and vibrations resulting from road traffic can be neglected.

\subsection{Assessing the vulnerability of objectives in the area}

Considering the potential of liquefaction according to the particle size of rocks [4], a hazard classification of waste dumps was made according to the natural and anthropic objectives in the zone of influence and the liquefaction potential of the waste material (Table 1). There were five categories of vulnerability of objectives in the area to liquefaction, which were given values from 1 to 5,1 defining the very low vulnerability and 5 defining the very high vulnerability.

Table 1 Determining the vulnerability according to the liquefaction potential and the nature of the natural and anthropic objectives in the area

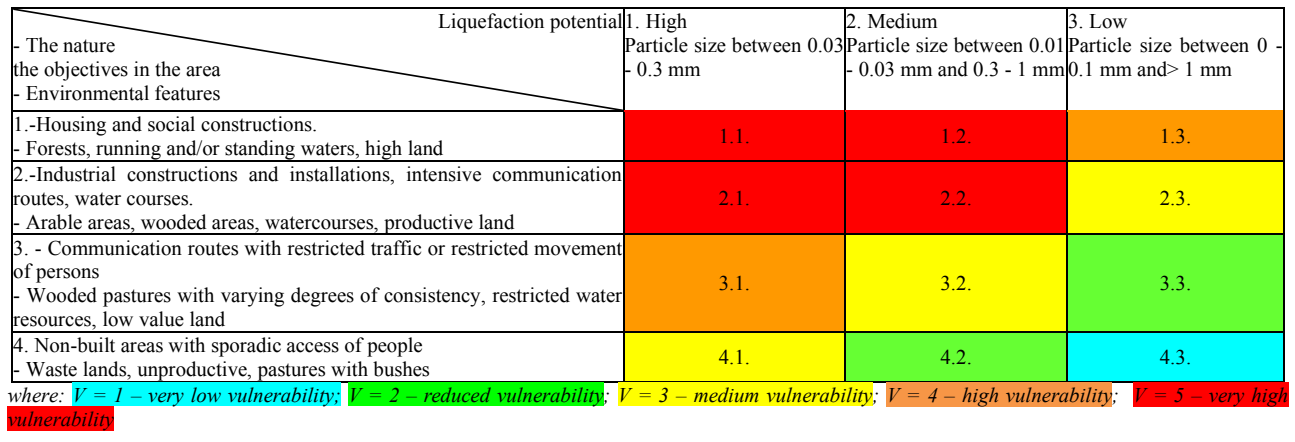


The sterile rocks consist of a complex of sedimentary rocks in different proportions: clayey rocks $(28.26 \%)$, marl $(12.72 \%)$, sandy rocks $(47.91 \%)$, gravel and rare boulders $(9.82 \%)$ and vegetal soil $(1.19 \%)$.

In the hypothesis that the dump is composed of the mixture of mentioned rocks, according to literature $[5,6]$ the fraction of about $30 \%$ of clay makes the waste material fall outside the category of liquefiable rocks.

In reality, however, the dump is represented by a succession of waste rocks. The problematic situation occurs when the final slopes or portions of the dump, which come into contact with the water in the lake, are made up of sandy rocks. Creating favorable conditions in these areas with the flooding of the remaining gap (sandy, loose and saturated rocks and the manifestation of water pressure in the pores) can influence the occurrence of the liquefaction phenomenon.

Analyzing all the granulometric curves obtained on the basis of granulometric analyzes performed in the laboratory, it was observed that there is still a balance between the granulometric distributions of the tested rocks (see Figure 1).

As a consequence, it is impossible to model the dump steps depending on the nature of the rocks, so the dump is considered to be composed of a mixture of rocks with varying particle sizes (from clays to sand and gravel) and medium uniformity.

By liquefaction an important volume of waste rocks can be trained. Considering the location and the way of development of the dump in the remaining gap of the North Pesteana quarry, the eventual liquefaction phenomena would primarily affect the material in the dump on the surface of which there are no objectives of major interest but only spontaneously installed vegetation.

According to table 1 and the scale chosen for the representation of vulnerability, the objectives in the area present low vulnerability to liquefaction $(\mathrm{V}=2)$.

\subsection{Assessing the probability of liquefaction}

Starting from the liquefaction classes established by Juang et al. [11], in order to estimate the probability of liquefaction, these were defined by a series of evaluation criteria: the predominant granulometric fraction, the degree of nonuniformity, the type of granulometric curve [4], the degree of loosening [12], the degree of saturation, roughness and degree of rounding of rock granules (Table 2). A probability assessment scale has been set, comprising values from 1 to 5,1 defining the improbability of the liquefaction phenomenon and 5 defining the very high probability of liquefaction.

Table 2 Estimation of liquefaction probability

\begin{tabular}{|c|c|c|c|c|c|}
\hline Description & $\begin{array}{lr}\text { Very } & \text { high } \\
\text { probability } & \text { of } \\
\text { liquefaction } & \\
\end{array}$ & $\begin{array}{l}\text { High probability of } \\
\text { liquefaction }\end{array}$ & $\begin{array}{l}\text { Medium probability } \\
\text { of liquefaction }\end{array}$ & $\begin{array}{l}\text { Low probability of } \\
\text { liquefaction }\end{array}$ & $\begin{array}{l}\text { Very low probability } \\
\text { of liquefaction }\end{array}$ \\
\hline & $\begin{array}{l}\text { Almost sure the } \\
\text { waste material will } \\
\text { liquefy }\end{array}$ & $\begin{array}{l}\text { It is very likely that } \\
\text { the waste material } \\
\text { will liquefy }\end{array}$ & $\begin{array}{l}\text { Liquefaction or not of } \\
\text { the waste material is } \\
\text { equally probable }\end{array}$ & $\begin{array}{l}\text { It is unlikely that the } \\
\text { waste material will } \\
\text { liquefy }\end{array}$ & $\begin{array}{l}\text { Almost sure that the } \\
\text { waste material will } \\
\text { not liquefy }\end{array}$ \\
\hline & $\mathrm{P}_{\mathrm{L}}>0.85$ & $0.65<\mathrm{P}_{\mathrm{L}} \leq 0.85$ & $0.35<\mathrm{P}_{\mathrm{L}} \leq 0.65$ & $0.15<\mathrm{P}_{\mathrm{L}} \leq 0.35$ & $\mathrm{P}_{\mathrm{L}} \leq 0.15$ \\
\hline Evaluation criteria & $\mathrm{Pr}=5$ & $\mathrm{Pr}=4$ & $\mathrm{Pr}=3$ & $\operatorname{Pr}=2$ & $\mathrm{Pr}=1$ \\
\hline $\begin{array}{l}\text { The predominant } \\
\text { granulometric } \\
\text { fraction }\end{array}$ & $100 \%$ sand & $\begin{array}{c}50-100 \% \text { sand }+ \\
\text { important dust } \\
\text { fractions }\end{array}$ & $\begin{array}{l}50-100 \% \text { dust }+ \\
\text { important sand } \\
\text { fractions }\end{array}$ & $50-100 \%$ clay & $100 \%$ clay \\
\hline $\begin{array}{l}\text { The degree of } \\
\text { nonuniformity } \\
\text { The type of } \\
\text { granulometric curve }\end{array}$ & $\begin{array}{l}\text { very uniformly } \\
\text { very steep slope }\end{array}$ & $\begin{array}{l}\text { uniform } \\
\text { steep slope }\end{array}$ & $\begin{array}{l}\text { medium uniformity } \\
\text { balanced slope }\end{array}$ & $\begin{array}{l}\text { nonuniform } \\
\text { smooth curve }\end{array}$ & $\begin{array}{l}\text { very nonuniform } \\
\text { very smooth curve }\end{array}$ \\
\hline $\begin{array}{l}\text { The degree of } \\
\text { loosening }\end{array}$ & $\begin{array}{c}=1,31-1,38 \\
\text { initial }\end{array}$ & $\begin{aligned}= & 1,16-1,31 \\
& <\text { initial }, \\
> & \text { remanent }\end{aligned}$ & $\begin{array}{c}=1,10-1,16 \\
\text { remanent }\end{array}$ & $\begin{array}{c}=1,005-1,10 \\
<\text { remanent }\end{array}$ & $\begin{array}{l}=1,005 \\
\text { non-loose }\end{array}$ \\
\hline $\begin{array}{l}\text { The degree of } \\
\text { saturation }\end{array}$ & \multicolumn{2}{|c|}{ saturated } & very moist & moist & dry \\
\hline Roughness & reduced & \multicolumn{3}{|c|}{ medium } & high \\
\hline Rounding degree & rounded & \multicolumn{3}{|c|}{ subrounded - subangular } & angular \\
\hline
\end{tabular}


According to the analyzes carried out on the samples taken from the North Pesteana perimeter and the data taken from the specialized studies, the liquefaction classes were made according to the probability of liquefaction. Considering the dump a mixture of waste rocks, according to the degree of nonuniformity, the degree of loosness, the roughness and the degree of rounding, the rocks have been classified as medium-liquefing rocks $(\operatorname{Pr}=3)$. From the point of view of the degree of saturation it is considered that the burial rocks are in a very wet to saturated state $(\operatorname{Pr}=4 \div 5)$. This condition describes the situation from the moment of flooding the remaining gap. Saturated waste material is an essential criterion in assessing the probability of liquefaction, as water is the main cause of the occurrence of these geotechnical phenomena. Knowing the content of sandy rocks $(\approx 50 \%-\operatorname{Pr}=4)$, it was estimated that there is a medium to high liquefaction probability of the waste material $(\mathrm{Pr}=$ $3 \div 4$ )

Considering the 5 vulnerability classes, respectively 5 probability classes, the following scale was established to assess the liquefaction risk:

- For $\mathrm{R}=1 \rightarrow$ very low risk of liquefaction;

- For $\mathrm{R}=2 \div 4 \rightarrow$ low risk of liquefaction;

- For $\mathrm{R}=5 \div 9 \rightarrow$ medium risk of liquefaction;

- For $\mathrm{R}=10 \div 15$ high risk of liquefaction;

- For $\mathrm{R}=16 \div 24 \rightarrow$ very high risk of liquefaction;

- For $\mathrm{R}=25 \rightarrow$ extremely high risk of liquefaction.

The risk of liquefaction phenomena was calculated at the inner dump in the North Pesteana perimeter. The result $(\mathrm{R}=\mathrm{V} \cdot \mathrm{Pr}=2(3 \div 4)=6 \div 8)$ indicates a medium risk of liquefaction.

\section{Solutions and measures to reduce the risk of liquefaction}

Among the measures to reduce the risk of liquefaction, the following are recommended: slope stabilization works (leveling, compaction, dynamic vibration stabilization, cementing of non-cohesive rocks) and works to accelerate the flooding process.

In order to minimize the risk of liquefaction of the waste material, it is recommended to apply the leveling and compacting measures of the berms and the slope surfaces. It is also recommended either selective dumping in the final slopes of the dump of a permeable material with large granulometry [13] or the planning of the storage in the dump of a balanced mixture of clayey, sandy and gravel rocks until cessation of activity. Thus, areas created exclusively from sandy rocks are avoided in the final slopes of the dump, which in contact with water can favor the manifestation of liquefaction phenomena. Another option is to build a supporting wall in front of the dump, but this option is more expensive.

In case of early-stage liquefaction, dynamic stabilization methods can be applied by vibration (Figure 2 - left) or by shot. [3] Figure 2 (right) shows how the "hidden" dike provides stability in case of liquefaction phenomena.
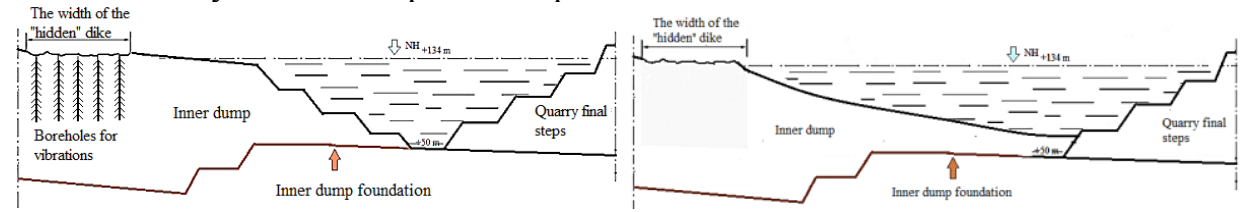

Fig. 2 Dynamic stabilization by vibration 
The main advantage is the increase of the rock resistance due to compacting and reduction of the porosity this process being influenced by the vibrations. Thus, in the case of the liquefaction phenomenon, the "hidden" dike provides a limit to which the waste material can be trained.

In the case of non-cohesive rocks, such as sands, which in the conditions of flooding of the remaining gap favor the manifestation of the liquefaction phenomena, it is recommended to carry out cementing works using a binder material.

A new Microbial Induced Calcite Precipitation stabilization method (MICP) has been tested for many applications in the geotechnical field (Figure 3). The results confirmed the potential of this method as a viable alternative technique including liquefied sand deposits, stabilization of slopes and surface consolidation. [14]

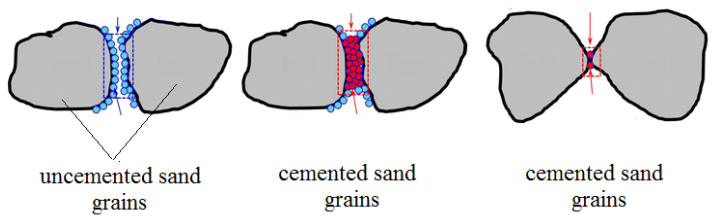

Fig. 3 Cementation of sandy granules using calcite as binder

According to the stability analyzes, it was found that the submersion of the final slopes of the remaining gap determines the increase of their stability reserve. The water pressure on the slope leads to increased resistance forces, opposed to sliding, and the water mass in the lake behaves like a bearing prism. So it is advisable to accelerate the process of flooding the remanent gap, a solution which can be materialized by the realization of a water supply system from the Jiu River, being the only permanent water source nearby. The amount of water that can be taken over can only be determined by the Romanian Waters Administration.

\section{Conclusions}

The sandy fraction existing in the inner dump of the North Pesteana quarry imposed the assessment of liquefaction risk in the conditions of the water level rise in the remaining gap and implicitly in the dump. The presence of water in the dump and the manifestation of pore water pressure are key factors in the production of the liquefaction phenomenon.

According to studies carried out on the geotechnical risk assessment in the conditions of flooding of the remaining gap of the North Pesteana quarry, it was found that there is a medium risk of liquefaction of the material dumped in the inner dump. The risk results from the fact that the waste rocks are in a loose state and are composed of important sand fractions. With the flooding of the remaining gap, the water level in the dump increases and the manifestation of pore water pressure in waste rocks favor the occurrence of the liquefaction phenomenon.

In order to minimize the risk of liquefaction, the appropriate measures are recommended and in this regard several solutions have been offered: leveling and compacting the slopes and berms, dynamic stabilization by vibrations and the creation of the hidden dike, cementation of non-cohesive rocks and acceleration of the flooding process.

The research presented in this paper has been conducted within the RAFF project (Risk Assessment of Final Pits During Flooding) co-financed by the Research Fund for Coal and Steel (RFCS) under the Grant Agreement No-847299-RAFF. 


\section{References}

1. N. Warraich, M.F. Baig, H.A. Rafique, Liquefaction of soil (Lahore Leads University, Lahore, 2014)

2. I. M. Apostu, F. Faur, MATEC Web of Conferences 290, 11002 (2019)

3. M. Weihrauch, Closure/Remediation of lignite mines (in German), 4th part (Verwajtungsgesel schaft mbH, Bergbau, 2006)

4. A. Marto, C.S. Tan, A.M. Makhtar, N.Z.M. Yunus, A. Amaludin, Malaysian Journal of Civil Engineering 25 (2), 189-199 (2013)

5. H. B. Seed, I.M. Idriss, Journal of Geotehnical Engineering 109 (3) (1983)

6. D. C. A. Andrews, G. R. Martin, Proceedings of 12 WCEE 7 (2000)

7. M.W. Herman, G.P. Hayes, G. M. Smoczyk, R. Turner, B. Turner, J. Jenkins, S. Davies, A. Parker, A. Sinclair, H.M. Benz, K.P. Furlong, A. Villaseñor, Seismicity of the Earth 1900-2013, Mediterranean Sea and vicinity: U.S. Geological Survey Open-File Report 2010-1083-Q (2015)

8. ***, Analysis and statistics of earthquakes Romania (in Romanian) (Romania, 2018) https://www.snas.ro/

9. ***,World Earthquakes (2018) https://www.world-earthquakes.com/

10. ***, National Institute of Physics of the Earth (INFP) (in Romanian) (Romania, 2018) http://www.infp.ro/despre-cutremure/\#ch 10

11. C.H. Juang, J. Ching, Z. Luo, Georisk: Assessment and Management of Risk for Engineered Systems and Geohazards, 7 (3), 137-150 (2013)

12. A. Todorescu, Properties of rocks (in Romanian) (Tehnical PH, Bucharest, 1984)

13. M. Lazar, Degraded lands rehabilitation (in Romanian) (Universitas PH, Petrosani, 2010)

14. L.Cheng, R. Cord-Ruwisch, M. A. Shahin Canadian Geotechnical Journal, 50 (1), 81-90 (2013) 